\title{
Incidentally Found Retroperitoneal Ganglioneuroma in an Adult
}

\author{
Asli Koktener • Dilek Kosehan • Kayihan Akin • \\ Mikdat Bozer
}

Received: 17 February 2010 / Accepted: 8 June 2010 / Published online: 5 January 2014

(C) Association of Surgeons of India 2014

\begin{abstract}
The ganglioneuroma is a very rare tumor arising from sympathetic nerve system. An asymptomatic retroperitoneal ganglioneuroma was found incidentally in a 35 -yearold woman. Ultrasonography, computed tomography, and magnetic resonance imaging showed a retroperitoneal mass extending to the left adrenal gland, and surrounding abdominal aorta, celiac axis, left renal and adrenal arteries, and veins. The tumor was resected and histologic examination showed ganglioneuroma.
\end{abstract}

Keywords Ganglioneuroma - Retroperitoneal mass · Computed tomography $\cdot$ Magnetic resonance imaging

\section{Introduction}

Retroperitoneal ganglioneuromas are rare benign tumors originating in the sympathetic ganglion. They usually arise from paravertebral sympathetic plexus and occasionally from the adrenal medulla. Most ganglioneuromas are asymptomatic and found incidentally. The most common site of occurrence is the retroperitoneum and mediastinum [1,2]. We describe incidentally found retroperitoneal ganglioneuroma with imaging finding on ultrasonography, computed tomography, and magnetic resonance imaging.

\footnotetext{
A. Koktener $(\bowtie) \cdot$ D. Kosehan $\cdot$ K. Akin

Department of Radiology, School of Medicine, Fatih University, Alparslan Turkes Cad. No. 57, Emek, 06510 Ankara, Turkey

e-mail: akoktener@yahoo.com

\section{Bozer}

Department of Surgery, School of Medicine, Fatih University, Ankara, Turkey
}

\section{Case report}

A 35-year-old female presented with fatigue, back pain, and pollakuria. Her laboratory test was normal except low hemoglobin level. Abdominal ultrasonography (US) showed retroperitoneal hypoechoic, well-defined mass, $4 \mathrm{~cm}$ in diameter with paraceliac location. Abdominal dynamic computed tomography (CT) showed a retroperitoneal mass surrounding celiac axis, displacing left surrenal gland, and minimal enhancing after contrast material injection (Fig. 1). Magnetic resonance (MR) imaging determined a retroperitoneal mass surrounding major blood vessels, and abdominal aorta, filling left adrenal region. It is homogenous hypointense relative to the liver on $\mathrm{T} 1$ and heterogenous hyperintense relative to the liver on T2-weighted images. Contrast-enhanced MR images showed minimal enhancement of this part of the mass (Fig. 2).

Following these findings, the patient underwent a laparotomy. A bilobulated mass was observed just beside the left surrenal gland. Frozen section revealed a mesenchymal tumor. The mass was excised with the adrenal gland. Histopathologic examination demonstrated collections of spindle-shaped cells simulating the pattern of neurofibroma, and mature ganglion cells with large cytoplasm in the collagen stroma. Immunohistochemical staining showed positivities for vimentin, S 100 protein, nerofilament protein in the spindle-shaped schwanian cells. Ganglion cells showed staining for synaptophysin, chromogranin, cathepsin $\mathrm{D}$, and S 100 protein. The final diagnosis was ganglioneuroma.

\section{Discussion}

Ganglioneuromas are rare, benign neurogenic tumors, often asymptomatic. When they have metabolic activity caused by catecholamines, vasoactive intestinal polypeptides, or androgenic hormones, hypertension, diarrhea, and virilization may 


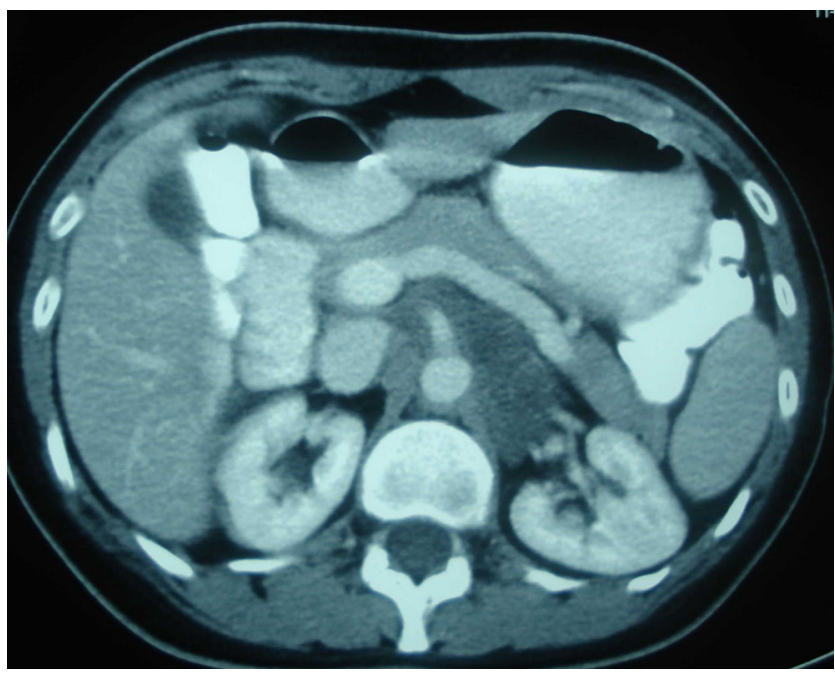

Fig. 1 Contrast-enhanced CT scan showing poorly enhanced retroperitoneal mass surrounding abdominal vessels

be seen $[3,4]$. Otherwise, compressive symptoms-related mass size may occur [5]. The most of the ganglioneuromas are found incidentally on abdominal imaging.

Ganglioneuromas may occur anywhere along the sympathetic plexus, and occasionally in the adrenal medulla, of neural crest origin. The tumors are composed of mature Schwan cells (mature stroma), ganglion cells, and nerve fibers [1]. Cellular atypia, mitotic activity, and necrosis are not seen. They are rarely composed of phechromocytoma, ganglioneuroblastoma, and neuroblastoma elements and transform to malignant peripheral sheath tumor [6].

Children and young adults are predominantly affected. Posterior mediastinum, retroperitoneum, pelvis or neck, or gastrointestinal tract may be involved [6,7].

US, CT, and MR imaging show well-circumscribed, oval, crescentic, or oval lobulated mass. US reveals a homogenous, hypoechoic mass. At unenhanced CT, ganglioneuromas are low attenuation, homogenous. Fine and speckled calcification may be seen in about $20 \%$ of cases [8]. They tend to surround or displace major blood vessels, but without compression or occlusion $[1,9]$. Because of the myxoid matrices in the tumor, delayed heterogenous enhancement occur by contrast medium.

At MR imaging, ganglioneuroma has low signal intensity on T1-weighted images and heterogenous high signal intensity on T2-weighted images. Heterogenous signal intensity depends on the combination of myxoid material and ganglion cells. As at CT, ganglioneuromas usually demonstrate delayed enhancement $[1,8,10]$.

In one study, $57 \%$ of patient with ganglioneuroma showed uptake of tracer iodine-123 metroiodobenzyl guanidine. Most of these tumors produced increased amount of catecholamines [2].

The treatment of retroperitoneal mass is complete surgical excision, if possible. Because of the slow progression
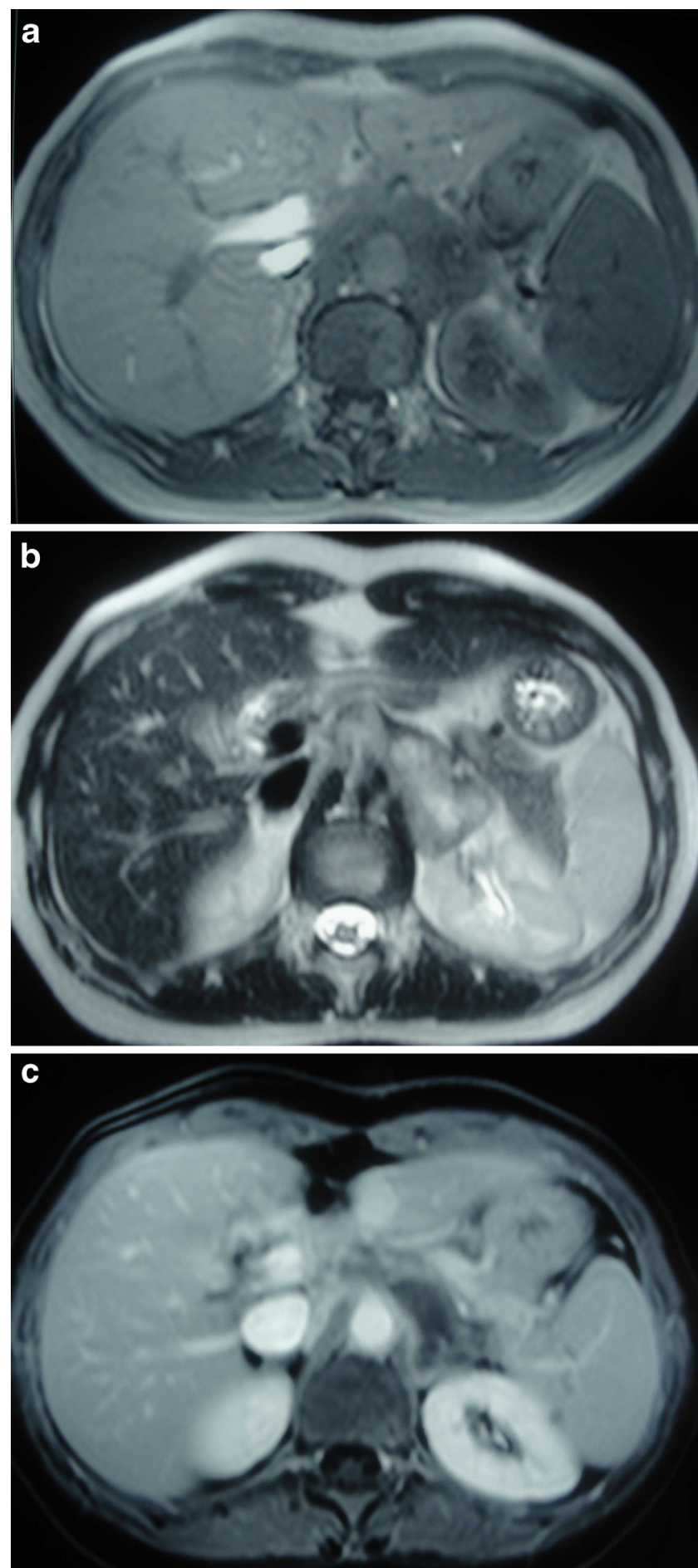

Fig. 2 a Axial T1-weighted MR image showing retroperitoneal mass with hypointense relative to the liver, $\mathbf{b}$ hyperintense mass on axial T2weighted MR image, and $\mathbf{c}$ after contrast material injection poorly enhanced mass on enhanced axial T1-weighted MR image

potential and late recurrence of ganglioneuroma, long-term follow-up is necessary $[2,11]$.

Adrenal lesions are less than $40 \mathrm{~mm}$ in diameter and nonfunctioning are suitable for close follow up, without operation. Lesions with a diameter greater than $60 \mathrm{~mm}$ and with 
malignancy suspicion of tumors 40 to $60 \mathrm{~mm}$ in diameter should be treated with open adrenalectomy. Laparoscopic adrenalectomy can be applied to the tumors 40 to $60 \mathrm{~mm}$ in diameter without malignant characteristics $[12,13]$.

Ganglioneuroma is relatively difficult to distinguish from other tumors since specific finding is not sufficient to diagnose. However, it must be included in the differential diagnosis of retroperitoneal masses.

\section{References}

1. Rha SE, Byun JY, Jung SE, Chun HJ, Lee HG, Lee MJ (2003) Neurogenic tumors in the abdomen: tumor types and imaging characteristics. Radiographics 23:29-43

2. Geoerger B, Hero B, Harms D, Grebe J, Schiedhauer K, Berthold F (2001) Metabolic activity and clinical features of primary ganglioneuromas. Cancer 91:1905-1913

3. Radin R, David CL, Goldfarb H, Francis IR (1997) Adrenal and extra-adrenal retroperitoneal ganglioneuroma: imaging findings in 13 adults. Radiology 202:703-707

4. Moriwaki Y, Miyake M, Yamamoto T et al (1992) Retroperitoneal ganglioneuroma: a case report and review of the Japanese literature. Intern Med 31:82-85
5. Nishinari K, Wolosker N, Yazbek G, Nakagawa WT, Lopes A (2003) Idiopathic aneurysm of inferior vena cava associated with retroperitoneal ganglioneuroma: case report. J Vasc Surg 37:895-898

6. Lonergan GJ, Scwab CM, Suarez ES, Carlson CL (2002) Neuroblastoma, ganglioneuroblastoma, and ganglioneuroma: radiologic-pathologic correlation. Radiographics 22:911-934

7. Cobellis L, Messalli EM, Rossiello R, Montone L, Cobellis G (2004) Bilateral pelvic ganglioneuroma: clinicopathologic findings. Eur $\mathrm{J}$ Obstet Gynecol Reprod Biol 117:242-244

8. Ichikawa T, Ohtomo K, Araki T, Fujimoto H, Nemoto K, Nanbu A et al (1996) Ganglioneuroma: CT and MR features. Br J Radiol 69: 114-121

9. Otal P, Mezghani S, Maleux G, Colombier D, Rousseau H, Joffre F (2001) Imaging of retroperitoneal ganglioneuroma. Eur Radiol 11: 940-945

10. Serra AD, Rafal RB, Markisz JA (1992) MRI characteristics of two cases of adrenal ganglioneuromas. Clin Imaging 16:37-39

11. Keller SM, Papazoglou S, McKeever P, Baker A, Roth JA (1984) Late occurrence of malignancy in a ganglioneuroma 19 years following radiation therapy to a neuroblastoma. J Surg Oncol 25:227-231

12. Yamaguchi K, Hara I, Takeda M, Tanaka K, Yamada Y, Fujisawa M et al (2006) Two cases of ganglioneuroma. Urology 67:622.e1$622 . e 4$

13. National Institutes of Health: National Institutes of Health State-ofthe-Science Statement (2002) Management of the clinically in apparent adrenal mass (incidentaloma). Available at: http://consensus.nih. gov/ta/021/021_sttatement.htm. Accessed July 7,2005. 